\title{
Reproducibility of flow rates measured with low density gas mixtures in exercise-induced bronchospasm
}

\author{
STEPHEN G SPIRO, C WARREN BIERMAN, IAN S PETHERAM \\ From the Department of Respiratory Medicine, Rayne Institute, University College Hospital, London
}

ABSTRACT We have studied the reproducibility of the change in maximum expiratory flow rates after $\mathrm{C}_{\mathrm{N}}^{\infty}$ breathing helium/oxygen $\left(\mathrm{He} / \mathrm{O}_{2}\right)$ mixtures in 12 asthmatics at rest and after exercise. Each subject O performed four identical exercise tests which caused a similar degree of exercise-induced $\rightarrow$ bronchospasm (EIB) on each occasion. We compared flow rates at $50 \%$ of the vital capacity (ن் 50$) Z$

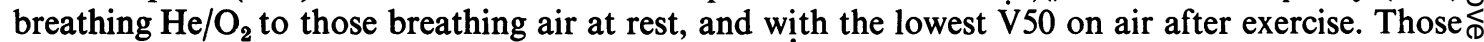
subjects showing an increase of greater than $20 \%$ in $\mathrm{V} 50$ with $\mathrm{He} / \mathrm{O}_{2}$ compared to the correspond- $\frac{}{0}$

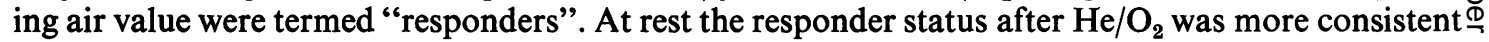
than during EIB. Six subjects were non-responders consistently on up to 12 separate measurements $\vec{\bullet}$ at rest while the other five subjects were non-responders on all but one occasion and the remaining $\stackrel{\infty}{-}$ subject a responder on seven of eight measurements. During EIB all but one subject showed a $\mathrm{He} / \mathrm{O}_{2}$. response. A response was seen consistently in six subjects but the actual percentage change in $\dot{V} 50$ with helium varied greatly. One subject remained a non-responder after exercise and the other five $\frac{\bar{O}}{0}$ were $\mathrm{He} / \mathrm{O}_{2}$ responders after only two or three of the four test runs, and non-responders on the remainder. The lack of consistency of our data, particularly during EIB makes the interpretation $\stackrel{\odot}{\circ}$ of the $\mathrm{He} / \mathrm{O}_{2}$ breathing test less useful than originally claimed.

An increase in maximum expiratory flow rate at the mid vital capacity point ( $\mathbf{V} 50)$ after breathing a low density gas mixture $(80 \%$ helium, $20 \%$ oxygen, $\mathrm{He} / \mathrm{O}_{2}$ ) compared to $\dot{V} 50$ breathing air has been proposed as a method for identifying the major site of airflow obstruction. ${ }^{1}$ After breathing $\mathrm{He} / \mathrm{O}_{2}$, subjects with an increase in V50 greater than $20 \%$ have been termed "responders" and this is interpreted as indicating that the major site of resistance to airflow lies in large airways where gas flow is turbulent and density dependent. Those with an increase in V50 less than $20 \%$ or with no change have been termed "non-responders" and this indicates that resistance to airflow lies predominantly in small airways where gas flow is laminar and density independent. Response to breathing $\mathrm{He} / \mathrm{O}_{2}$ has been studied in asthmatic subjects after recovery from spontaneous exacerbations, ${ }^{2}$ antigen-induced attacks, ${ }^{3}$ and exercise-induced bronchospasm ${ }^{4}$ (EIB). Recent applications of the technique have attempted

Address for reprint requests: Stephen G Spiro, Department of Respiratory Medicine, Rayne Institute, University College Hospital, London WC1E 6AU. to identify the predominant site of action of anticholinergic agents and disodium cromoglycate as a protection for EIB. These have shown differento음 effects dependent on the initial responder status of $\underset{\times}{\stackrel{0}{x}}$ the subject. ${ }^{5}$ However, despite wide acceptance of 0 this test as a method of determining the major site of resistance to airflow there are few published data $\bigcirc$ on the reproducibility of response to breathing $\mathrm{He} / \mathrm{O}_{2}$ during EIB. We report studies on 12 asth-o matic subjects each of whom performed four $D$ identical exercise tests to assess the reproducibility of을 response to breathing $\mathrm{He} / \mathrm{O}_{2}$ at rest and during $\mathrm{EIB}$ and investigate factors that might cause variability $\%$ in individuals.

\section{Methods}

The subjects were young volunteers whose main symptom was wheezing after exertion. Their personal ${ }^{+}$ details together with resting lung function on entry뭉 to the study are summarised in table 1 . Mean values? for forced expiratory volume in one second $\left(F E V_{1}\right) \stackrel{?}{?}$ vital capacity (VC), and peak expiratory flow rate $\Omega$ 
Table 1 Details of subjects (mean $\pm S E M$ )

\begin{tabular}{llllllll}
\hline Number & Age $(y r)$ & Male & Female & $\begin{array}{l}\text { FEV }(l) \\
\% \text { predicted }\end{array}$ & $\begin{array}{l}\text { FVC }(l) \\
\% \text { predicted }\end{array}$ & $\begin{array}{l}\text { PEFR }(l / s) \\
\% \text { predicted }\end{array}$ & $\begin{array}{c}\dot{V_{50}}(l) \\
\% \text { predicted }\end{array}$ \\
\hline 12 & $26(2 \cdot 4)$ & 7 & 5 & $84(3 \cdot 8)$ & $95(2 \cdot 9)$ & $111(5 \cdot 2)$ & $57(6 \cdot 4)$ \\
\hline
\end{tabular}

(PEFR) were within $20 \%$ of predicted but the group mean V50 was reduced. None was taking oral corticosteriods, 10 were using aerosol bronchodilators, and seven disodium cromoglycate. All medication was withheld for at least 12 hours before any study. Each exercise test was performed on an automated treadmill for six minutes employing a modification of a standardised protocol. ${ }^{6}$ Subjects qualified for the study with an initial screening test to determine the speed and angle of the treadmill belt necessary to produce a heart rate $90 \%$ of predicted maximum and to verify that an exercise-induced fall of at least $20 \%$ in $F E V_{1}$ developed after exercise. Each subject performed four exercise tests at the same time of day at least two days apart employing the speed and incline determined by the screening run. Lung function measurements were obtained from forced VC expirations into a dry wedge spirometer attached to a microprocessor system (Oldelft, "Floop") which also recorded the maximum expired flow volume (MEFV) curve from each VC manoeuvre. Paired expiratory manoeuvres were performed, firstly breathing air, and secondly after breathing the $\mathrm{He} / \mathrm{O}_{2}$ mixture for one minute which was terminated by three $\mathrm{VC}$ inspirations then forced expiration into the spirometer. If the $\mathrm{VC}$ after breathing the helium mixture was not within $5 \%$ of the VC after breathing air it was discarded and the procedure repeated. Before exercise two or three paired air and helium manoeuvres were recorded but after exercise, since frequent measurements were made to follow the evolution of response of $\dot{V} 50$ to breathing $\mathrm{He} / \mathrm{O}_{2}$, only a single pair of measurements was made at each time point. Measurements were made at rest, immediately after exercise, and at $3,5,10,15$, and 20 minutes. The exercise tests were performed in a centrally heated laboratory with an ambient temperature of $19-21^{\circ} \mathrm{C}$, but no attempts were made to control the environment closely.

Analysis of the reproducibility of response to breathing $\mathrm{He} / \mathrm{O}_{2}$ was performed in two stages. Reproducibility at rest was assessed by the percentage change in $\dot{V} 50$ in each subject studied on many occasions. Reproducibility after exercise was assessed by percentage change of $\dot{\mathrm{V}} 50$ after $\mathrm{He} / \mathrm{O}_{2}$ at the nadir of $\dot{V} 50$.

Any effect on response status by breathing $\mathrm{He} / \mathrm{O}_{2}$ for different durations was also studied in a subgroup of the patients who breathed $\mathrm{He} / \mathrm{O}_{2}$ for one minute and three VC breaths, three minutes and three VC breaths, and for only three VC breaths. Predicted normal values were taken from Cotes. ${ }^{\text {? }}$

Statistical analysis was performed on the resting data to estimate the variance and to test the homogeneity of the values in order to establish the expected error that could be obtained on any
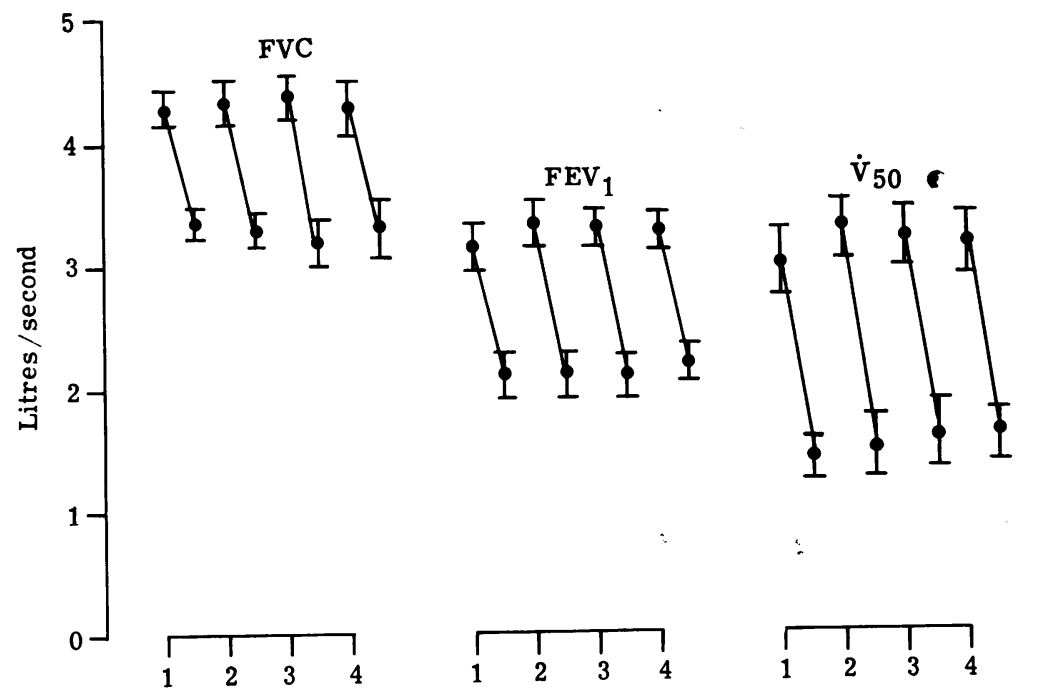

Fig 1 Mean ( $\pm S E M)$ values for $F V C, F E V_{1}$, and $\dot{V} 50$ breathing air for the 12 subjects at rest and the point of lowest $\dot{V} 50$ after exercise for each of the four test runs.
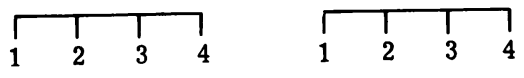

Exercise Tests 
Table 2 Reproducibility of $\mathrm{He} / \mathrm{O}_{2}$ response at rest before four exercise tests

\begin{tabular}{|c|c|c|c|c|c|}
\hline Subject & $\begin{array}{l}\text { Number of } \\
\text { manoeuvres }\end{array}$ & $\begin{array}{l}\text { Mean viso (air) } \\
(l / s \pm S D)\end{array}$ & $\%$ predicted & $\begin{array}{l}\text { Mean } \Delta \text { V Vंo } \\
( \pm S D)\end{array}$ & $\begin{array}{l}\text { No. } \Delta \text { Vं50 } \\
>20 \% \text { after } \\
\mathrm{He} / \mathrm{O}_{2}\end{array}$ \\
\hline 1 & 8 & $3.49(1.0)$ & 64 & $+9.6(9.14)$ & 1 \\
\hline 2 & 12 & $4.60(0.39)$ & 113 & $-\quad 2.9(8.64)$ & 0 \\
\hline 3 & 10 & $2.71(0.38)$ & 53 & $+5.3(6.04)$ & 0 \\
\hline 4 & 11 & $2.79(0.48)$ & 46 & $-4.5(7.53)$ & 0 \\
\hline 5 & 10 & $2.54(0.32)$ & 49 & $+9.1(6.63)$ & 1 \\
\hline 6 & 8 & $3.08(0.53)$ & 61 & $+24.8(30.88)$ & 7 \\
\hline 7 & 11 & $3 \cdot 10(0 \cdot 29)$ & 62 & $\begin{array}{r}5.2(10.02) \\
+\end{array}$ & 1 \\
\hline 8 & 12 & $2.06(0.19)$ & 38 & $\begin{array}{r}5.1(14.24) \\
+\end{array}$ & 1 \\
\hline 9 & 12 & $1.94(0.57)$ & 39 & $-12 \cdot 1(11.54)$ & 0 \\
\hline 10 & 12 & $1.88(0.29)$ & 34 & $-12.2(7.72)$ & 0 \\
\hline 11 & 12 & $4.07(0.42)$ & 79 & $+10.9(10.31)$ & 3 \\
\hline 12 & 8 & $3.19(0.31)$ & 63 & - $7.4(11.29)$ & 0 \\
\hline
\end{tabular}

measurement.

\section{Results}

The group mean values before each of the four exercise tests and mean of the lowest of these measurements after exercise are summarised in fig 1. Before each exercise test lung function for each subject was within $10 \%$ of the value obtained before the screening run and the exercise protocol used produced highly reproducible falls in lung function.

HELIUM RESPONSIVENESS AT REST

The $\mathrm{He} / \mathrm{O}_{2}$ responses for each subject at rest are summarised in table 2 . Only six of the 12 subjects $(2,3,4,9,10$, and 12$)$ showed a consistent pattern of response and always had changes of less than $20 \%$ for $\mathrm{V} 50$ after $\mathrm{He} / \mathrm{O}_{2}$ breathing. The other six subjects were less consistent since four showed changes of less than $20 \%$ except on one occasion and subject 6 (the only "responder") increased $\dot{V} 50$ by more than $20 \%$ on seven of eight occasions. Subject 11 showed greatest variability with an increase of $\dot{V} 50$ less than $20 \%$ on nine occasions but more than $20 \%$ on three occasions.

Estimates of the patient variation of the percentage difference in air and $\mathrm{He} / \mathrm{O}_{2}$ flow rates were reasonably homogeneous as confirmed by a KolmogorovSmirnov test giving a value for $\mathrm{Z}$ of $1.07(\mathrm{p}<0.2)$. Therefore the overall standard deviation for any observation was estimated by pooling the individual patients' standard deviations giving a resultant value for variation of $12.9 \%$. This must be considered a high value in relation to the defined $20 \%$ change between responder and non-responder status.

HELIUM RESPONSIVENESS DURING EXERCISEINDUCED BRONCHOSPASM

Figure 2 shows percentage increase in $\dot{V} 50$ after breathing $\mathrm{He} / \mathrm{O}_{2}$ at the nadir of $\dot{\mathrm{V}} 50$ in those six subjects who increased $\dot{V} 50$ consistently by more than $20 \%$ after each of four exercises tests. Although these subjects were consistent "responders" the

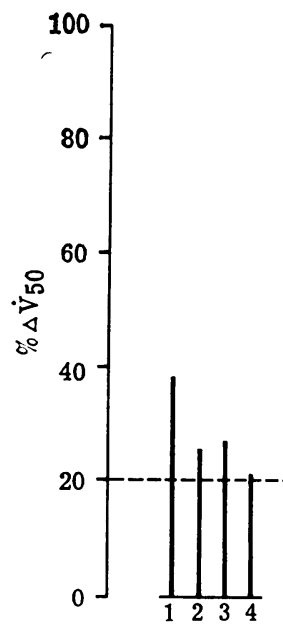

Subject Number

2

\begin{abstract}
4
\end{abstract}

\begin{abstract}
6
\end{abstract}

\begin{abstract}
9
\end{abstract}
11

12 




Fig 3 Variation in percentage increase in $\dot{V} 50$ after breathing $\mathrm{He} / \mathrm{O}_{2}$ in each of the six subjects who failed to show an increase of $20 \%$ on at least one occasion during EIB.

Subject Number

\section{Table 3 Effect of duration of breathing $\mathrm{He}_{2} \mathrm{O}_{2}$ gas mixtures on responsiveness}

\begin{tabular}{|c|c|c|c|c|c|c|c|c|c|}
\hline \multirow{2}{*}{$\begin{array}{l}\text { Duration of } \\
\text { breathing } \mathrm{He} / \mathrm{O}_{2}\end{array}$} & \multicolumn{4}{|c|}{ Subjects at rest } & \multicolumn{5}{|c|}{ Subjects after exercise } \\
\hline & 1 & 2 & 3 & 4 & 5 & $I$ & 2 & 5 & 6 \\
\hline $\begin{array}{l}3 \mathrm{VC} \text { only } \\
1 \mathrm{~min}+3 \mathrm{VC} \\
3 \mathrm{~min}+3 \mathrm{VC}\end{array}$ & $\begin{array}{l}+\quad 6 \%(2) \\
+15 \%(2) \\
-13 \%(2)\end{array}$ & $\begin{array}{r}+19 \%(2) \\
+\quad 7 \%(2) \\
+13 \%(4)\end{array}$ & $\begin{array}{l}-7 \%(1) \\
-8 \%(1) \\
-9 \%(1)\end{array}$ & $\begin{array}{l}- \\
+10 \%(2) \\
+\quad 3 \%(2)\end{array}$ & $\begin{array}{l}+24 \%(2) \\
+35 \%(2) \\
+25 \%(2)\end{array}$ & $\begin{array}{l}- \\
-12 \%(1) \\
2 \%(2)\end{array}$ & $\begin{array}{l}-3 \%(2) \\
0 \%(2)\end{array}$ & $\begin{array}{l}-\quad 6 \%(1) \\
+\quad 23 \%(2)\end{array}$ & $\begin{array}{l}-7 \%(2) \\
-9 \%(2)\end{array}$ \\
\hline
\end{tabular}

( ) Indicate number of studies.

percentage increase in $\dot{\mathrm{V}} 50$ after $\mathrm{He} / \mathrm{O}_{2}$ varied widely in some subjects-for example, 9 and 12 . The other six subjects were "non-responders" on some occasions and their data are summarised in fig 3. The percentage increase in $\dot{V} 50$ after $\mathrm{He} / \mathrm{O}_{2}$ varied very widely in some of these subjects $(1,3,8$, and 10). One subject (7) failed to sdow an increase in $\dot{\mathrm{V}} 50$ after $\mathrm{He} / \mathrm{O}_{2}$ on each occasion after exercise.

\section{EFFECT OF DURATION OF BREATHING $\mathrm{He} / \mathrm{O}_{2}$}

Table 3 shows percentage change in $\dot{V} 50$ after breathing $\mathrm{He} / \mathrm{O}_{2}$ for the periods shown at rest or during EIB in six of the subjects. Breathing $\mathrm{He} / \mathrm{O}_{2}$ for three minutes rather than one minute caused no consistent difference to the percentage change in $\dot{V} 50$ for five of the subjects at rest nor during EIB for three of four subjects. The only inconsistency was subject 5 who showed a $\mathrm{He} / \mathrm{O}_{2}$ response after three minutes of breathing $\mathrm{He} / \mathrm{O}_{2}$ but not after breathing it for one minute. Three $\mathrm{VC}$ breaths alone at rest in four subjects also showed responses consistent with the measurements made after the longer periods of $\mathrm{He} / \mathrm{O}_{2}$ breathing.

\section{SEVERITY OF OBSTRUCTION AND HE/O2 RESPONSIVENESS}

As airways obstruction became more severe ( $\dot{V} 50$ lower) the percentage response of $\dot{\mathrm{V}} 50$ was more variable. At the lowest levels of $\dot{V} 50$ breathing air the percentage change varied from about $20 \%$ to $95 \%$ and this occurred in the same subject. There was no relationship between decreasing V50 breathing air and the $\mathrm{He} / \mathrm{O}_{2}$ response. Figure 4 shows percentage change in $\dot{\mathrm{V}} 50$ after $\mathrm{He} / \mathrm{O}_{2}$ breathing for subjects in whom $\mathrm{VC}$ fell by identical amounts from resting values at the nadir of $\dot{V} 50$ after at least two of the four exercise runs. In six subjects when VC fell identically the percentage change in $\dot{V} 50$ after $\mathrm{He} / \mathrm{O}_{2}$ breathing was similar (subjects 2, 5, 7 (twice), and 11 (twice) ). In five subjects change in $\dot{V} 50$ varied more widely $(6,3,1,8,9)$ despite similar (within $3 \%$ ) changes in VC and in four $(1,5,8,10)$ despite identical changes in VC, the change in $\dot{V} 50$ was so variable as to alter "response" status.

\section{Discussion}

Although the $\mathrm{He} / \mathrm{O}_{2}$ breath test has become an accepted method of identifying the major site of airways obstruction, its reproducibility has not been carefully examined. The heterogeneity of responses within groups of asthmatics ${ }^{2-48}$ with similar resting lung function to those in the present study persuaded us to investigate this.

The $\mathrm{He} / \mathrm{O}_{2}$ response was more variable in the 




patients after exercise than at rest. Only seven of the 12 subjects had a consistent response after exercise, including subject 7 who remained a non-responder. However, the percentage change in $\dot{V} 50$ after $\mathrm{He} / \mathrm{O}_{2}$ varied considerably for each individual and widely for these seven subjects as a group (fig 2). In the other five patients the responder status itself was inconsistent with a response of less than $20 \%$ on at least one occasion, and twice for two of the subjects (fig 3). The range of percentage change in $\dot{V} 50$ after $\mathrm{He} / \mathrm{O}_{2}$ was also large. Although an increased flow rate of at least $20 \%$ after $\mathrm{He} / \mathrm{O}_{2}$ has been suggested as the standard for a "responder" status, ${ }^{1}$ this is a somewhat arbitrary definition and others have used different percentage increases. ${ }^{2}$ The percentage change after $\mathrm{He} / \mathrm{O}_{2}$ measured in our subjects after exercise was so diverse that any other definition of a "responder" based on larger or smaller increases in $\dot{\mathrm{V}} 50$ after $\mathrm{He} / \mathrm{O}_{2}$ would not have changed the inconsistency of our data substantially.

The $\mathrm{He} / \mathrm{O}_{2}$ changes measured at rest were less variable than those after exercise. More pairs of MEFV curves were available at rest as at least two pairs were performed before each period of exercise. Only six patients showed consistency and were nonresponders after each pair of curves. There was a change in response status on at least one occasion for each of the other six patients. However, the response status was reasonably reproducible as four of the six patients who showed a change in status did so only once in eight to 12 measurements (table 2), and the actual percentage change in $\mathrm{V} 50$ after $\mathrm{He} / \mathrm{O}_{2}$ was much smaller than during EIB.

The reasons for the majority of our patients being $\mathrm{He} / \mathrm{O}_{2}$ non-responders at rest is not obvious although their low resting $\dot{\mathrm{V}} 50$ is suggestive of predominant small airways obstruction, but it is an observation at variance with other studies where the majority of mild asthmatics were responders. ${ }^{1-3}$ The increase in responder status and percentage increase in $\dot{V} 50$ with $\mathrm{He} / \mathrm{O}_{2}$ after exercise has been previously noted. 148 However, the reported association of decreasing $\mathrm{He} / \mathrm{O}_{2}$ response with increasing severity of airways obstruction ${ }^{2}$ was not noted in this study, nor in other reports. ${ }^{19}$ The period breathing $\mathrm{He} / \mathrm{O}_{2}$ has varied from two to 10 minutes in other patient studies, ${ }^{389}$ and was confined to only three VC manoeuvres in a study of normal subjects. ${ }^{10}$ As we intended to make frequent measurements after exercise in order to measure the $\mathrm{He} / \mathrm{O}_{2}$ response at the nadir of EIB, we chose a breathing period of one minute. There was no evidence from other studies that the duration of $\mathrm{He} / \mathrm{O}_{2}$ breathing appeared critical to the development of the response but all studies have included three VC manoeuvres. We observed no differences in the responses of a subgroup of patients tested at rest and the result was similar for three of four subjects after exercise (table 3).

Another possible cause of the present measurements differing from other reports was that the MEFV curves were measured with a spirometer rather than a plethysmograph. However, the possible differences in flow rates because of gas compressibility which affect measurements made within a plethysmograph have already been systematically studied and were shown to alter the $\mathrm{He} / \mathrm{O}_{2}$ response status in only one of 31 patients with asthma. ${ }^{2}$ Since spirometry only was used, changes in total lung capacity or residual volume after exercise could not be measured. 
However, this study was confined to reporting changes with $\mathrm{He} / \mathrm{O}_{2}$ in pairs of matched MEFV curves at rest and after exercise, and not changes in flow rates between rest and exercise, as in the latter knowledge of lung volume changes become important. There is no information on the consistency of lung volume changes after repeated episodes of EIB. In our patients the percentage fall in $F E V_{1}$ and PEFR for each subject was very consistent and in 10 subjects the drop in $\mathrm{VC}$ at the lowest V50 was identical after at least two tests. It could be assumed that where VC changes were identical with similar falls in $F E V_{1}$, the lung volume changes should also be similar. Even in these tests the change in V 50 after $\mathrm{He} / \mathrm{O}_{2}$ showed considerable variability and was unrelated to the decrease in VC (fig 4). Thus it appears that the intrasubject variation with $\mathrm{He} / \mathrm{O}_{2}$ after exercise was not caused by differences in lung volume.

The measurements of changes in the MEFV curve after $\mathrm{He} / \mathrm{O}_{2}$ seemed unreliable in normal subjects ${ }^{10}$ and $\mathrm{He} / \mathrm{O}_{2}$ response has been shown to correlate poorly with airways resistance. ${ }^{8}$ The $\mathrm{He} / \mathrm{O}_{2}$ response test is either too inconsistent to differentiate large from small airways obstruction reliably in EIB, or the patients themselves may vary so much that the interpretation of the $\mathrm{He} / \mathrm{O}_{2}$ test is far more complex than originally proposed.

This work was supported in part by Janssen Pharmaceutical Limited. We are grateful for the advice given by Dr S Freedman, and for the help of $\mathrm{Mr} \mathrm{A}$ Cobley and Miss Angela Betchley.

\section{References}

${ }^{1}$ Despas PJ, Leroux M, Macklem PT. Site of airway obstruction in asthma as determined by measuring maximal expiratory flow breathing air and a helium/ oxygen mixture. J Clin Invest 1972;51:3235-43.

${ }^{2}$ Benatar SR, Clark TJH, Cochrane GM. Clinical response to low density gas breathing in asthmatics. Am Rev Respir Dis 1975;111:126-34.

${ }^{3}$ Cheng Yeung M, Abboud R, Tsao MS, Maclean L. Effect of helium on maximal expiratory flow in patients with asthma before and during induced bronchoconstriction. Am Rev Respir Dis 1976;113:433-43.

${ }^{4}$ McFadden ER Jr, Ingram RH Jr, Haynes RL, Wellman JJ. Predominant site of flow limitation and mechanisms of post exertional asthma. J Appl Physiol: Respirat Environ Exercise Physiol 1977;42:746-52.

5 Thomson NC, Patel KR, Kerr JW. Sodium cromoglycate and ipratropium bromide in exercise-induced asthma. Thorax 1978;33:694-9.

- Eggleston P, Guerrant JL. A standardized method of evaluating exercise-induced asthma. $J$ Allerg Clin Immunol 1976;58:414-25.

7 Cotes JE. Lung function. Assessment and application in medicine. Fourth edition. Oxford: Blackwell, 1979.

${ }^{8}$ Mildon A, Leroux M, Hutcheon M, Zamel N. The site of airways obstruction in exercise-induced asthma. Am Rev Respir Dis 1974;110:409-14.

${ }^{9}$ Antic R, Macklem PT. The influence of clinical factors on site of airways obstruction in asthma. Am Rev Respir Dis 1976;114:851-60.

10 Macdonald JB, Cole TJ. The flow-volume loop: reproducibility of air and helium-based tests in normal subjects. Thorax 1980;35:64-9. 